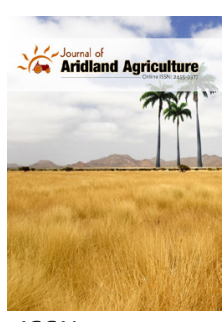

ISSN: $2455^{-9} 9377$

\title{
Potential of sand as a medium of water evaporation - A Review
}

\author{
Natasya Ghinna Humaira1, Abdul Hamid², Sarwoko Mangkoedihardjo** \\ 'Department of Environmental Engineering, Institut Teknologi Sepuluh Nopember (ITS), Surabaya, Indonesia, \\ ${ }^{2}$ Head of East Java Province Library and Archives Service, Jalan Menur Pumpungan 32, Surabaya, Indonesia
}

Received: August 19, 2020 Revised: November 20, 2020 Accepted: November 22, 2020 Published: December 05, 2020

*Corresponding Author: E-mail: prosarwoko@gmail. com

\begin{abstract}
The purpose of this review is to give an up to date overview of the existing literature on water evaporation from the sand. The paper summarizes the factors influencing evaporation rates in water evaporation from sand such as solar radiation, air temperature, air moisture, the temperature at the water-table, relative humidity of the air, depth of the ground water table, wind speed, vapor pressure difference, sand capillary, hydraulic conductivity and particle size of sand. Limitations and constraints identifying existing gaps are discussed, as well as the potential applicability.
\end{abstract}

KEYWORDS: Sand, evaporation, influence factors, potential applicability

\section{INTRODUCTION}

Evaporation from porous media is a common process important for industrial processes such as drying of foods and building materials, and many environmental applications and hydrological processes such as evapotranspiration. Evaporation from soil affects energy balance, land surface-atmosphere interactions, and agricultural water management and influences many biological activities in the vadose zone. Most evaporation processes from porous media can be viewed as an immiscible displacement process [1]. The study of this process has significant practical benefits in various fields: predicting evaporation flux in design of soil cover of mine tailings [2-4], investigating the long-term performance of moisture-retaining soil covers [5], designing evapotranspiration cover systems for waste containment and mining sites [6], classifying landfill sites according to climatic water balance [7], etc. Moreover, the investigation of soil water evaporation is also an important issue in geotechnical engineering. For bare soils, the water evaporation process is controlled by both atmospheric conditions and soil conditions $[3,8,9]$. The objective of this study was to investigate the mechanisms of water evaporation from sand and the factors influencing evaporation rates in water evaporation from sand, as well as the potential applicability.

\section{Heat Conductance}

Every material or material such as oil, water, metal, iron, aluminium, copper, sand and others have different heat conductivity values. Sand can transform sunlight energy into thermal energy greater than soil and red brick [10]. Coastal sand is generally poor in nutrients, has a fast infiltration rate, sandy soil texture, loose and single-grained soil grains and low water-holding ability and low chemical fertility and high soil temperature [11-13]. According to Buckman and Brady [14], Hanks \& Arschoft [15], and Hillel [16] the sand is dominated by macro pores so that water that falls into sandy soil will immediately undergo percolation and capillary water will easily escape due to evaporation.

Heat transfer from sand to water is about 150 times faster than from sand to air. If the water content in the sand increases, the air in the sand will decrease so that the resistance to conduction or conductance of heat will be low. In general, sand has a very low content of organic matter so that the soil temperature is very high. Some physical properties of sand such as heat volumetric capacity, thermal conductivity and thermal diffusivity are also known as sand thermal properties [16]. These three properties of sand affect the heat transfer and dynamics of water transfer to and from the soil. Evaporation which is the process of transferring water mass from the sand into the atmosphere is greatly influenced by the internal factors of the sand, especially by the three physical properties of the sand. While external factors are energy to the surface of the sand, the depth of the sand and relative humidity above the surface of the sand that causes changes in sand temperature [17]. Sand temperature is related to the absorption of solar radiation by the soil. The absorption of radiation itself depends on the water content in the soil.

In general, the average sand temperature is greater than the temperature of the surrounding atmosphere. This is caused

Copyright: $\odot$ The authors. This article is open access and licensed under the terms of the Creative Commons Attribution License (http://creativecommons.org/licenses/by/4.0/) which permits unrestricted, use, distribution and reproduction in any medium, or format for any purpose, even commercially provided the work is properly cited. Attribution - You must give appropriate credit, provide a link to the license, and indicate if changes were made. 
by storing heat in the sand longer than in the air. Because the propagation of heat into the soil requires time, the soil temperature at each deeper depth experiences a reduction. The temperature distribution in sand depends on several factors, including thermal conductivity, volumetric heat capacity, and soil colour [18]. The use of sand itself is intended so that when the intensity of solar radiation decreases, the sand is expected to heat up the fluid flowing in the absorbing pipe. Energy input from the sun changes with time and is generally not according to need, so we need a kind of heat storage media [19].

\section{Water Evaporation}

Evaporation from porous media involves mass and energy transportation including phase changes, vapor diffusion, and liquid flow, producing complex displacement patterns that affect the rate of evaporation. The force balance considers the properties of the media that can affect the transition in the evaporation rate from the liquid-based first stage which is limited by the exchange of steam with air to the second stage which is controlled by the diffusion of steam through the media [20]. Initially, the rate of evaporation from saturated porous media is rather high and relatively constant (called evaporation stage 1) largely limited by meteorological factors, followed by lower evaporation values (called stage evaporation 2) which is limited by the nature of porous media transportation [20-23]. In porous media the evaporation process is controlled by atmospheric conditions (meteorology) and media conditions [2,3,8,9].

The rate of evaporation is influenced by meteorological factors (humidity, temperature, and air velocity around the pore space of the media) and the properties of conductivity transport (thermal, hydraulic conductivity and steam diffusion). As a result, complex and highly dynamic interactions between media properties, transportation processes, and boundary conditions produce evaporation $[21,24]$. The way to maintain a constant evaporation rate during step 1 is hydraulically continuous liquid path persistence through capillary-induced fluid flow from larger pores on the dry surface to finer water-filled pores on the evaporation surface $[20,22,25,26]$. Stage 2 evaporation is characterized by the receding fluid surface of the media and forming a dry layer that interferes with continuity [26-29]. Understanding the dynamics of continuity of the liquid phase pathway is important to illustrate the evolution of salt deposition and concentration distribution during evaporation from porous media [30,31].

\section{Influence Factors}

Evaporation on porous media, water evaporation process is controlled by atmospheric or meteorological conditions, such as solar radiation, temperature, relative humidity, wind speed, etc., and porous media conditions, such as texture, initial water content, hydraulic conductivity and water retention capacity $[2-4,8,9,32,33]$. The following explanation of the evaporation factors in porous media:

1. Solar radiation

Solar radiation is a major factor influencing evaporation rates. Evaporation rates and air temperatures are the result of the energy supplied by solar radiation [34,35]. High clean solar radiation can produce high latent heat fluxes which can therefore increase evaporation rates, most evaporation occurs during the daytime $[7,36]$. The high rate of evaporation is directly proportional to high solar radiation $[6,37]$.

2. Air temperature

High temperatures can produce high evaporative rates as well $[1,6,37,38]$. However, air temperatures affect evaporation indirectly due to increased evaporation and air temperature are energy obtained from solar radiation $[35,39,40]$.

3. Temperature on the surface of the water

Water temperature at the surface of the water affects the evaporation of sand indirectly due to increased evaporation and air temperature is the energy obtained from solar radiation. Rising temperatures on the surface of the water is directly proportional to rising temperatures, and vice versa [35].

4. Relative humidity of the air

An increase in relative humidity decreases the rate of evaporation and vice versa $[6,29,37]$. The relative humidity value of the air at different elevations becomes the evaporation factor. Evaporation of water from the sand causes the relative humidity of the air near the ground surface higher than in other elevations. This relative moisture difference will continue to occur when the water needs to evaporate sufficiently. Along with the evaporation process, sand surface resistance to evaporation is increased and the amount of moisture coming into the air decreases. Thus, the relative humidity difference at different elevations decreases. Finally, the evaporation of the water will cease when the vapor pressure of the sand becomes equal to the surrounding air [4]. On the other hand, from the evolution of relative humidity, the effect of air temperature and the rate of air flow on evaporation can also be observed, at the same airflow rate, the higher the temperature of the air in the chamber, the lower the humidity relative in space. At the same air temperature, the lower airflow rate only raises a slightly higher relative humidity [41].

In contrast to the results of the research of Davenport [34] and Hickman [42] that there is no direct correlation between relative humidity and evaporation because the relationship of the effect of relative humidity on various evaporation and other climatic factors is much more influential on the evaporation process.

5. Wind speed

Evaporation rates are high at high wind speeds [6,37]. Evaporation rates are sensitive to wind velocity at the beginning of the process when the surface of the porous media is wet $[29,43]$, whereas an increase in wind speed results in a reduction in evaporation rate when the surface of the porous media is dry [44]. Wind speed has a considerable influence on evaporation, especially when air humidity is relatively high at the test site [35].

6. Height of water level

The water level significantly influences the evaporation process [5]. The air content in the zone close to the surface decreases rapidly at the beginning of evaporation and then gradually decreases, the deeper the air level the lower the evaporation rate. The effect of ambient conditions on evaporation decreases with decreasing water level [45-47]. 
This is consistent with the results of Hellwig's study [48] that maintaining the air surface $30 \mathrm{~cm}$ below the sand surface reduces evaporation from the sand of average diameter $0.32 \mathrm{~mm}$ to about $50 \%$ of the open air surface. Maintaining an air level $60 \mathrm{~cm}$ below the sand surface reduces evaporation from the sand of average diameter $0.53 \mathrm{~mm}$ to $10 \%$ of the exposed air surface. Other research says that evaporation from the surface of the water on the surface of the sand is $8 \%$ lower than the surface of open water [35].

7. Difference in vapor pressure

Evaporation is directly proportional to the difference in vapor pressure except in tests carried out at high humidity $[40,49]$. Evaporation stops when the vapor pressure on the surface of a porous medium becomes equal to air [4].

8. Sand particle size

Evaporation decreases faster with increasing size of sand that is inversely proportional [48]. Internal factors of sand can be ignored if the surface of the water is on the surface of the sand. Significantly internal factors of sand can affect the rate of evaporation, if the water level is below the surface of the sand. In this case the factor of increasing sand capillarity will increase evaporation. This is consistent with the description of the evaporation process which considers the decline in groundwater levels by Koliasev [50], Hide [51] and Gardner [52].

9. Capillary sand

Monitoring the capillary fluid path continuously in the process of drying the porous media front is a way to understand evaporation and the mechanism of pore scale mass transport [1]. The sand is dominated by macro pores so that water falling into the sand will immediately percolate and water on the capillaries will be easily loose because of evaporation [14-16]. The evaporation rate is likely to be limited by a diffusive exchange at the top of the air boundary layer above the water surface $[28,53]$. The larger the size of the sand the evaporation rate will decreasing [48]. Distribution of substances from the inside to the surface with a higher concentration of the substance is in the finepore sand, indicating preferential flow in the water-filled fine pores connected to the evaporation surface [54].

10. Changes in water content

Basically, evaporation of ground water causes a decrease in water content, volumetric water content in the near surface zone decreases rapidly at the beginning of evaporation and then decreases gradually. In addition, deeper zones begin to lose water only when evaporation lasts a long time. This phenomenon can be launched by the resistance of soil evolution to evaporation [9,32]. The trend of decreasing evaporation was also observed by Wythers et al. [32] in plate evaporation experiments. If the water content in the sand increases, the air in the sand will decrease so that the resistance to conduction or heat delivery will be low, the heat absorption in the sand will be lower [16].

11. Hydraulic conductivity

The hydraulic conductivity coefficient is one of the most important soil properties, because it controls the flow of water [4l]. Reducing saturated hydraulic conductivity can speed up time for high-level evaporation.

\section{Media temperature}

Temperature in the sand can be influenced by the intensity of solar radiation. The heat-off into the sand takes time, so the temperature of the sand at each deeper depth has a reduction. This can be proved by the research conducted by Hellwig [35]. The media temperature is strongly influenced by air conditions. When the air temperature is high, the temperature of the sand rises and heat energy to evaporate solely from the hot air. Conversely, when the air temperature is low, energy for evaporation comes from the air and sand. Evaporation process also affects the temperature of sand: When the evaporation rate is low, the energy consumed by evaporation is reduced, so the temperature of sand increases due to hot air heat [41].

13. Distribution of chemical substances

In pore scale substance distribution dynamics, during evaporation stage 1 which is defined by a continuous liquid structure, the solute will be directed to the evaporation surface by capillary flow. Thus, the concentration of the substance on the surface increases continuously with increasing time. The spatial distribution of the liquid phase at the surface and its downward connectivity form the accumulation of substances in the surface area. In the macroscopic scale of substance distribution dynamics, surface evaporation significantly influences the dynamics of solute concentration. This proves that evaporation occurs only in water [1].

\section{Potential Applicability}

The potential for sand to store and transfer heat is effective for water-unsaturated medium. Here it is concerned with the condition of Indonesia, however, it can be used for any place in the appropriate area. In the condition, especially for solving environmental problems, some potential applications of sand as an evaporation medium are as follows.

1. On-site sanitation system is commonly used as a means of managing human waste in urban and rural areas in Indonesia. There are two systems, namely:

a. Evaporation bed system. This system allows wastewater to flow into the septic tank, and the waste is discharged through the soil absorption system. Soil absorption can be a mound of sand as a wastewater evaporator, called evaporation bed.

b. Evapotranspiration bed system. To be able to increase the flow of water into the air, the evaporation bed is overgrown with plants, making it an evapotranspiration bed. This system is very easy to modify from the evaporation bed, and has become important in the era of the COVID-19 pandemic and beyond. Since this pandemic era, everyone must use personal protection, the essential thing is a mask, keep distance and personal hygiene and other inanimate objects. This essential requirement results in the addition of wastewater, which is enriched with antiseptic and disinfectant substances. The quality of wastewater is effectively improved using plant processing [55] to absorb chlorides, and together with root microbes can degrade organic substances. 
The advantage of the evaporation and evapotranspiration of wastewater is reducing the amount of wastewater infiltration into groundwater, so that groundwater pollution can be reduced. Likewise, the existence of unsaturated conditions, allows the process to run aerobically, therefore organic wastewater materials can be degraded properly.

2. The handling of leachate resulting from municipal waste degradation is also still problematic. Leachate treatment processes require precision leachate quality. The process can be aided by reducing leachate flow. In this connection is the use of sand as a leachate evaporation medium. In accordance with the research of Marks et al. [56] treatment of leachate by evaporation can reduce most of the amount of water in leachate proportional to the high rate of evaporation, so that it can reduce the processing load compared to conventional processing. The evaporation process will produce leachate concentrate. The resulting concentrate will contain most of the contaminants and will be a fraction of the original leachate volume. Leachate treatment by evaporation allows the reduction of volatile organic compounds such as ammonia and organic acids from leachate and from nonvolatile components such as heavy metals and other solids, thus affecting the quality of the leachate.

\section{CONCLUSIONS}

Evaporation from porous media involves mass and energy transportation including phase changes, vapor diffusion, and liquid flow, and produces complex displacement patterns that affect the rate of evaporation. Evaporation from porous media has 2 stages namely the rate of evaporation from high saturated porous media and is relatively constant. It is called evaporation stage 1 , which is largely limited by meteorological factors. Then followed by lower evaporation values. It is called evaporation stage 2 , which is limited by the nature of transportation porous media. In a practical sense the use of sand for the evaporation medium is to use unsaturated conditions, so that heat can be stored by sand and transferred to water to evaporate.

\section{REFERENCES}

1. Shokri, N., Lehmann, P., \& Or, D. (2010). Evaporation from layered porous media. Journal of Geophysical Research: Solid Earth, 115(6), $1-12$.

2. Wilson, G.W. (1990). Soil evaporative fluxes for geotechnical engineering problems. PhD. thesis, Department of Civil Engineering, University of Saskatchewan, Saskatoon, Sask.

3. Wilson, G.W., Fredlund, D.G., \& Barbour, S.L. (1994). Coupled soilatmosphere modelling for soil evaporation. Canadian Geotechnical Journal, 31(2): 151- 161

4. Yanful, E.K., \& Choo, L.-P. (1997). Measurement of evaporative fluxes from candidate cover soils. Canadian Geotechnical Journal, 34(3): 447-459.

5. Yang, M., \& Yanful, E.K. (2002). Water balance during evaporation and drainage in cover soils under different water table conditions. Advances in Environmental Research, 6(4): 505-521.

6. Cui, Y.-J., \&Zornberg, J.G. (2008). Water balance and evapotranspiration monitoring in geotechnical and geoenvironmental engineering. Geotechnical and Geological Engineering, 26(6): 783-798.

7. Blight, G.E. (1997). Interactions between the atmosphere and the Earth. Géotechnique, 47(4): 715-767.

8. Qiu, G.Y., Yano, T., \& Momii, K. (1998). An improved methodology to measure evaporation from bare soil based on comparison of surface temperature with a dry soil surface. Journal of Hydrology, 210(1-4): 93-105.

9. Van de Griend, A.A., \& Owe, M. (1994). Bare soil surface resistance to evaporation by vapor diffusion under semiarid conditions. Water Resources Research, 30(2): 181-188.

10. Kresnawati, Fitrya. (2008). Transformasi Energi Cahaya Matahari Menjadi Energi Termal Pada Bahan Pasir, Tanah, Dan Bata Merah.

11. Darmawijaya, I. (1998). Dasar-dasar klasifikasi tanah. Gadjah Mada University Press, Indonesia

12. Gustafon. (1962). Soil management. Mc Graw Hill Book Company Inc., New York

13. Wambeke, A.N. (1992). Soil of the tropics properties and appraised. Mc Graw Hill Inc. New York.

14. Buckman dan Brady. (1980). The nature and properties of soils. Mc Millan Company, New York.

15. Hanks, R.J., \& Ashcroft, G.L. (1980). Physical properties of soil Springer- Verlag. Berlin.

16. Hillel, D. (1998). Pengantar fisika Tanah, Mitra Gama Widya, Yogyakarta.

17. Mawardi, M. (2003). Perubahan sifat thermal tanah pasiran akibat penambahan bahan organik. Lembaga Penelitian UGM.

18. Tjasjono (1999). Klimatologi umum. Penerbit ITB, Bandung.

19. Siswantoro, B. Raharjo, N. Bintoro dan P. Hastuti. (2008). Model Matematik Transfer Panas Pada Penggorengan Menggunakan Pasir. Makalah. Disajikan pada Prosiding Seminar Nasional Teknik Pertanian yang diselenggarakan oleh Universitas Gadjah Mada. Yogyakarta. 18-19 November 2008.

20. Lehmann, P., Assouline, S., \& Or, D. (2008). Characteristic lengths affecting evaporative drying of porous media. Physical Review E Statistical, Nonlinear, and Soft Matter Physics, 77(5), 1-16.

21. Van Brakel, J. (1980). Mass transfer in convective drying. In Mujumdar, A.S. (Ed.), Advances in Drying. Vol. 1, pp. 217-267, Hemisphere, Washington, DC.

22. Scherer, G. W. (1990). Theory of drying, J. Am. Ceram. Soc., 73, 3-14.

23. Shokri, N., P. Lehmann, \& D. Or . (2009). Characteristics of evaporation from partially wettable porous media, Water Resources Research, 45, W02415

24. Prat, M. (2002). Recent advance in pore-scale models for drying of porous media. Chemical Engineering Journal 86 (1-2) : 153-164.

25. Laurindo, J. B., \& M. Prat (1998), Numerical and experimental network study of evaporation in capillary porous media: Drying rates, Chem. Eng. Sci., 53, 2257-2269.

26. Shokri, N., P. Lehmann, \& D. Or (2009). Critical evaluation of enhancement factors for vapor transport through unsaturated porous media, Water Resources Research, 45, W10433.

27. Saravanapavan, T., \& G. D. Salvucci. (2000). Analysis of rate $\square$ limiting processes in soil evaporation with implications for soil resistance models, Advanced Water Resource, 23, 493-502.

28. Shokri, N., P. Lehmann, \& D. Or (2008), Effects of hydrophobic layers on evaporation from porous media, Geophysics Research Letter, 35 L19407.

29. Yamanaka, T., \& T. Yonetani (1999), Dynamics of the evaporation zone in dry sandy soils, Journal of Hydrology. Amsterdam, 217, 135-148.

30. Goncalves, T.D., Pel, L. \& Rodrigues, J.D. (2007). Drying of saltcontaminated masonry: MRI laboratory monitoring. Environ Geol $52,293-302$

31. Le, D., Hoang, H. \& Mahadevan, J .(2009). Impact of Capillary-Driven Liquid Films on Salt Crystallization. Transport Porous Media, 80, 229.

32. Wythers, K.R., Lauenroth, W.K., \& Paruelo, J.M. (1999). Bare-soil evaporation under semiarid field conditions. Soil Science Society of America Journal, 63(5): 1341-1349.

33. Wang, W.Z. (2006). Wind tunnel experiments on bare soil evaporation M.Sc. thesis, Department of Civil Engineering, National Central University, Taiwan

34. Davenport, D.C., (1967). Variations of evaporation in time and space, 1. Study of diurnal changes using evaporimeters and grass lysimeters. Journal of Hydrology, 5: 312-328, 1967.

35. Hellwig, D. H. R. (1973). Evaporation of water from sand, 1: Experimental set-up and climatic influences. Journal of Hydrology, 18(2), 93-108.

36. Aluwihare, S., \& Watanabe, K. (2003). Measurement of evaporation on bare soil and estimating surface resistance. Journal of Environmental Engineering, 129(12): 1157-1168. 
37. Cui, Y.-J, Lu, Y.F., Delage, P., \& Riffard, M. (2005). Field simulation of in situ water content and temperature changes due to groundatmospheric interactions. Géotechnique, 55(7): 557-567.

38. Or, D., Lehmann, P., \& Shokri, N. (2007). Characteristic lengths affecting evaporation from heterogeneous porous media with sharp textural boundaries. Estudios de La Zona No Saturada Del Suelo, VIII, $1-8$.

39. Skinbiewski, L., (1953). Factors influencing the intensity of evaporation from the lakes of the Polish Lowland. Gaspodarka Wodna, Warsaw, 13: 209-210. Abstract in: Geza Turonyi: Part II. Ann. Bibliography on evaporation. Meteorology Abstract Bibliography, 10: American Meteorology Society, Boston, Massachusetts, (1959), pp. 1725-1765.

40. Shepherd, C.B., Hadlock, C. \& Brewer, R.C., (1938). Drying materials in trays - evaporation of surface moisture. Industrial \& Engineering Chemistry, 30: 388-397.

41. Song, W. \& Ding, W.-Q \& Cui, Y.. (2014). Experimental study on water evaporation from Fontainebleau sand using an environmental chamber. Shuikexue Jinzhan/Advances in Water Science. 25. 69-76.

42. Hickman, Jr., H.C., (1940). Evaporation experiments. Transactions of the American Society of Civil Engineers, 105: 807-849.

43. Kondo, J., Saigusa, N., \& Sato, T. (1992). A model and experimental study of evaporation from bare-soil surfaces. Journal of Applied Meteorology, 31(3): 304-312.

44. Yamanaka, T., Takeda, A., \& Sugita, F. (1997). A modified surface resistance approach for representing bare-soil evaporation: Wind tunnel experiments under various atmospheric conditions. Water Resources Research, 33(9): 2117-2128.

45. Houk, I.E., (1930). Discussion on R.L. Parshall, by letter. Transactions of the American Society of Civil Engineers, 94: 982-995.
46. Parshall, R.L., (1930). Experiments to determine rate of evaporation from saturated soils and river-bed sands. Transactions of the American Society of Civil Engineers, 94: 961-999.

47. Sleight, R.B., (1917). Evaporation from the surface of water and riverbed materials. Z Agriculture Research, 10:209-262.

48. Hellwig, D.H.R. (1973). Evaporation of water from sand, 4: The influence of the depth of the water table and the particle size distribution of the sand. Journal of Hydrology, 18: 317-327.

49. Hellwig, D. H. R. (1973). Evaporation of water from sand, 2: Diurnal variations. Journal of Hydrology, 18(2), 109-118.

50. Koliasev, F.E., (1941). Measures for the control of evaporation of soil moisture. Sbornik Rabot po Agronomicheskve, 3: 67-8i.

51. Hide, J.C., (1954). Observations on factors influencing the evaporation of soil moisture. Soil Science Society of America Proc., 18: 234-239.

52. Gardner, W.R., (1958). Some steady state solutions of the unsaturated moisture flow equation with application to evaporation from a watertable. Soil Science, 85 : 228-232.

53. Suzuki, M., \& S. Maeda (1968), On the mechanism of drying of granular beds-Mass transfer from discontinuous source, Journal of Chemical Engineering Japan, 1(1), 26-31.

54. Tuller, M., \& Or, D. (2001). Hydraulic conductivity of variably saturated porous media: Film and corner flow in angular pore space. Water Resources Research, 37(5), 1257-1276.

55. Samudro H. \& Mangkoedihardjo S. (2020). Greening the environment in living a new lifestyle in the COVID-19 era. EurAsian Journal of BioSciences, 14: 3285-3290.

56. Marks, A. L., Luthy, R. G., \& Diwekar, U. M. (1994). Semi-continuous evaporation model for leachate treatment process evaluation. Environmental Progress, 13(4), 278-289. 